\title{
As Leguminosas no Portugal Moderno: uma presença constante e discreta
}

\author{
Leguminous vegetables in Modern Portugal: a constant and discreet \\ presence
}

\section{Isabel Drumond Braga ${ }^{1}$}

\section{RESUMO}

Perante a impossibilidade de se conhecer o consumo per capita das diferentes leguminosas na Época Moderna, restam-nos fontes - livros de culinária, informações sobre dietas de estudantes, de religiosos e de presos, provérbios, relatos de viajantes estrangeiros, e outras - que permitem ter uma perceção qualitativa do uso das mesmas. A análise destas fontes diversas torna clara a maneira como foram entendidos estes alimentos, igualmente do ponto de vista dos consumos não prestigiantes, demonstrando o fraco valor simbólico da sua presença à mesa.

Palavras-chave: Brasil, Leguminosas, Portugal.

\section{ABSTRACT}

The impossibility of knowing the per capita consumption of the different leguminous vegetables in the Modern Age, we have sources - cookery books, student, religious and prisoners diets, proverbs, reports of foreign travellers, and others - that allow us to have a qualitative perception of their use. The analysis of these different sources makes clear the way in which these foods were understood, also from the point of view of the non-prestigious consumptions, demonstrating the weak symbolic value of their presence at the table.

Keyword: Brazil, Leguminous vegetables, Portugal.

1. 2016 foi escolhido pela 68. ${ }^{\mathrm{a}}$ Assembleia Geral das Nações Unidas, como o Ano Internacional das Leguminosas. Ao serem fonte de proteínas de origem vegetal e de aminoácidos devem ser consumidas pelos humanos de modo a obterem uma dieta saudável. 
Têm igualmente relevância na alimentação animal e propriedades fixadoras de nitrogénio que podem contribuir para aumentar a fertilidade dos solos, o que se traduz num impacto positivo no meio ambiente ${ }^{2}$. Neste sentido, ao longo do ano, Portugal esteve atento e desenvolveu diversas iniciativas com o objetivo de sensibilizar adultos e crianças para o consumo deste grupo de alimentos. Surgiram ações tão diversas como seminários, colóquios, tertúlias, produção de material didático, blogs e tantas outras ${ }^{3}$.

A atual roda dos alimentos dividiu-os em sete grupos (I - cereais e derivados e tubérculos, II - hortícolas, III - frutas, IV - lacticínios, V - carnes, pescados e ovos, VI - leguminosas, VII - gorduras e óleos) e previu o consumo diário de uma a duas porções de leguminosas, o que corresponde a três colheres de sopa, ou seja a 80 gramas e a quatro por cento do número de calorias ingeridas ${ }^{4}$. Basicamente, os benefícios do consumo espelham-se em oito pontos: são ricas em fibras solúveis permitindo o bom funcionamento intestinal, constituem uma importante fonte proteica, saciam bem, facilitando o controlo do apetite, possuem elevado teor em ferro contribuindo para combater a anemia, enquanto fontes de hidratos de carbono e de vitamina B facultam a produção de energia, apresentam um baixo índice glicémico uma vez que fornecem energia de forma gradual, a ingestão regular diminui a incidência de doenças cardiovasculares e têm preços acessíveis.

2. Recuemos, do ponto de vista da cronologia, para tentar perceber qual a relevância que os Portugueses deram ao consumo das leguminosas no passado a partir de fontes diversificadas - livros de cozinha, compilações de provérbios, livros de contas, visitas a conventos e ao Santo Ofício - cujas informações são apenas qualitativas. Na realidade, na falta de indicadores precisos acerca da produção, da importação e do consumo, importa tentar inquirir acerca das sensibilidades e das maneiras como as leguminosas foram vistas em termos de status. A indagação não está facilitada nem pelas fontes nem por estudos sobre o tema. Se no primeiro caso importa localizá-las, analisá-las e interpretá-las, no segundo, qualquer exploração tem-se mostrado completamente infrutífera.

Embora o nosso objeto de estudo esteja limitado ao espaço português na Época Moderna, vale a pena fazer mínimas incursões na Época Contemporânea, as quais permitem percecionar constantes estruturais. Vejamos três exemplos muito diferentes: a posição de um médico naturista, as observações de uma autora de um livro de culinária destinado a um público com exigências e uma alusão depreciativa num romance humorístico.

\footnotetext{
${ }^{2}$ Vejam-se as referências a este respeito, por exemplo, em < http://www.unric.org/pt/actualidade/32128-2016-e-anointernacional-das-leguminosas $>$. Consultado a 20 de setembro de 2016.

3 Vejam-se, por exemplo, <https://www.movimento2020.org/os-desafios/descubra-os-desafios-2020/aumentar-oconsumo-de-leguminosas $>$ ou <www.vidaativa.pt/a/importancia-das-leguminosas/ ou ainda http://www.colegiof3.ulisboa.pt/pt/nots/fava.php>, de entre muitos outros. Consultados a 20 de setembro de 2016.

4 Consulte-se, por exemplo, <http://www.dgs.pt/promocao-da-saude/educacao-para-a-saude/areas-deintervencao/alimentacao.aspx)>. Consultado a 20 de setembro de 2016
} 
O naturista Amílcar de Sousa (1876-1940), um dos pioneiros da defesa do vegetarianismo em Portugal, que dedicou a sua vida a escrever obras de divulgação, a proferir conferências e a colaborar em jornais e revistas os temas ligados ao vegetarianismo e ao naturismo, publicou em 1917, um pequeno artigo na revista $O$ Vegetariano, intitulado "Feijão". Apesar de praticar um regime frutívoro e crudívoro, nele salientou a importância da leguminosa desde que consumida sem exagero:

é necessário é não comer feijoada à bruta. Mas em doses moderadas, mesmo sem ser quotidiano, [os feijões] tornam o organismo bom e sadio. É um alimento de força, mesmo para trabalhadores de enxada e por isso os citadinos não devem abusar (SOUSA, 1917, p. 269).

Ou seja, Amílcar de Sousa, vegetariano que consumia quase exclusivamente frutas e todos os alimentos em cru, não deixou de reconhecer o papel das leguminosas e, neste caso, do feijão em concreto, como uma opção adequada para a alimentação humana, em especial dos que faziam esforços físicos consideráveis, tais como os trabalhadores rurais.

Com data de 1945, mas estando efetivamente disponível ao público a partir do final de janeiro do ano seguinte, apareceu $O$ Livro de Pantagruel, da autoria de Berta Rosa Limpo. Tratase de um dos mais conhecidos e vendidos livros de culinária portuguesa de todos os tempos, destinados a um público com exigências (BRAGA, CASTRO, 2013, 45-66). No prefácio, a autora esclareceu:

desde já [faço] notar-lhes que me abstive de incluir a maioria das receitas vulgares - o chamado 'trivial' - já por pertencer ao repertório de quantos livros se têm escrito sobre cozinha, já por ser conhecido de toda e qualquer banal cozinheira. Pareceu-me pelo menos inútil encher páginas e páginas com 'bacalhau com batatas', 'carneiro guisado com ervilhas' ou 'carapaus de escabeche', nas mesmas páginas em que poderei ensinar 'bacalhau de príncipe', 'polpettone', 'cannelloni' e outros que tais... (LIMPO, 1945, p. 10).

O mesmo tipo de discurso irá repetindo na sua coluna publicada na revista Modas $e$ Bordados: "não inclui essa receita [ervilhas guisadas] por ser um prato bastante vulgar e do 
conhecimento de quase todas as cozinheiras"5. Ou seja, no esclarecimento que fez acerca do tipo de obra que tinha escrito, a autora tornou claro que produzira um livro de culinária sofisticado, destinado a mulheres requintadas e exigentes, consequentemente as receitas vulgares estariam ausentes. $\mathrm{E}$, entre essas receitas triviais, contavam-se as que incluíam uma das leguminosas: ervilhas. Naturalmente que $O$ Livro de Pantagruel não foi uma obra contra a inclusão destas, apenas tornou claro que eram de consumo corrente e popular, em especial em pratos como os que enunciou, portanto, destinados a públicos mais simples.

Se tivermos em conta um outro tipo de fontes, designadamente a produção literária de um autor de sucesso da primeira metade do século XX, Armando Ferreira (1893-1968), poderemos perceber que a sua popularidade foi resultado de publicações humorísticas nas quais, em especial, procurou retratar tipos e costumes de Lisboa ${ }^{6}$. Inspirando-se na obra de Gervásio Lobato (1850-1895), Lisboa em Camisa, publicada em 1890, sobre uma família da pequena burguesia de Lisboa com pretensões (ESPERANÇO, 2017), Armando Ferreira produziu, de entre outras obras, uma trilogia intitulada Lisboa sem Camisa, composta por $O$ Casamento da Fifi Antunes (1935), O Baile dos Bastinhos (1936) e O Galã de Alcântara (1937)7.

Em O Casamento da Fifi Antunes, Moisés e Ludovina, os protagonistas, foram pais. Perante a necessidade de encontrar uma ama-de-leite para a criança, Fifi, a inépcia de Moisés Antunes ditou o insucesso da contratação e diversas peripécias que o levaram à esquadra. Antes, percebe-se o que deveria ser a alimentação da ama, segundo as exigências de uma das candidatas, que explicitou limitar-se a cuidar da criança e a comer à mesa com os donos da casa. Afastou qualquer hipótese de comer feijões e couves e exigiu leite de manhã e à noite, além de carne de vitela (FERREIRA, 1935, p. 48). Ou seja, para comer mal, comia em casa, não iria servir ninguém. E, na sua ótica, entre esses alimentos desinteressantes e correntes, contase uma leguminosa, o feijão.

Eis o mote, partindo de três fontes totalmente diferentes, para percecionar o pouco apreço pelas leguminosas nos receituários, em especial os que se destinavam a consumidores mais exigentes, e no imaginário do Portugal da primeira metade do século XX. Teria sido sempre assim?

\footnotetext{
${ }^{5}$ A autora incluiu o mesmo tipo de explicação na coluna "Correio de Pantagruel", que mantinha na revista feminina Modas e Bordados, n. ${ }^{\circ}$ 1786, Lisboa, 1 de maio de 1946.

${ }^{6}$ Este autor tem sido sistematicamente esquecido enquanto objeto de estudo, não tendo despertado o interesse dos autores do presente nem no âmbito da literatura nem da história. A única exceção é o trabalho que realizámos. Cf. BRAGA, 2017a. ${ }^{7}$ Se bem que este não seja o momento de avaliar a relevância da literatura como fonte histórica, recorde-se que abordar as representações através dos textos literários (CHARTIER 2000, pp. 197-216) constitui uma possibilidade para os historiadores, dando origem a profícuos diálogos entre as duas áreas do saber, que utilizam estratégicas retóricas diferenciadas ${ }^{7}$. Como Sandra Jatahy Pesavento chamou a atenção, "a História, tal como a Literatura, é uma narrativa que constrói um enredo e desvenda uma trama" (PESAVENTO, 2003, p. 33). Porém, as duas abordagens apresentam diferentes compromissos com a realidade, embora com recurso a discursos verosimilhantes, apesar de a História ter a pretensão de alcançar a verdade. Não obstante, a Literatura pode ser uma fonte histórica dependendo dos problemas formulados, designadamente se o objetivo for a perceção das sensibilidades, dos valores, das razões e dos sentimentos (PESAVENTO, 2003, p. 39).
} 
3. As leguminosas de uso corrente são: ervilha, fava, feijão, grão-de-bico, lentilha, tremoço e soja. Porém, na atualidade e no passado não colheram todas as mesmas simpatias e supõese, em consequência, o mesmo tipo de consumo. Esta hipótese advém, desde logo, da mais significativa menção a algumas delas. Por exemplo, para a Época Moderna, em Portugal, não se encontram referências a soja, enquanto ervilha, fava, feijão, grão-de-bico e lentilhas aparecem, algumas, inclusivamente, na preparação de pratos doces e de pratos salgados.

João Brandão de Buarcos, que calculou as quantidades produzidas ou vendidas dos mais diversos bens, em Lisboa, em meados do século XVI, não esqueceu uma das leguminosas. Efetivamente, sobre as favas, indicou que eram habitualmente comercializadas de forma ambulante, depois de preparadas, por mais de 50 negras, as quais também vendiam aletria, calculando que este comércio valia 5000 cruzados cada ano (BUARCOS, 1990, p. 73).

Muitos estrangeiros que visitaram Portugal foram autores de relatos tendenciosos, produzindo um tipo de narrativas que importa descodificar. Ao permaneceram por períodos variáveis no país, em alguns casos, essa situação impediu a compreensão cabal da realidade observada, levando-os a apresentar testemunhos superficiais e subjetivos resultantes de alguns preconceitos e influenciados por diversas leituras prévias ou posteriores às estadas (MARTINS, 2001, pp. 9-19; LIMA, 2007, pp. 175-178; ROSSATO, 2007, pp. 15-23, passim). Mesmo assim, as informações que apresentam podem ter alguma relevância. Por exemplo, no século XVIII, Link referiu-se às ervilhas portuguesas, que considerou inferiores às alemãs, e ao grãode-bico, que lhe pareceu aceitável (VELOSO, 1992, p. 53).

$\mathrm{Na}$ Época Moderna, os livros de cozinha impressos escassas referências fizeram às leguminosas e, quando tal aconteceu, limitaram-se à ervilha, à fava e ao grão-de-bico e mais raramente à lentilha. Vejamos, de forma mais cuidada, um exemplo. O primeiro livro de receitas culinárias impresso em Portugal foi a Arte de Cozinha, da autoria de Domingos Rodrigues, cuja primeira edição datou de 1680. Seguiram-se outras: 1683, 1693 (edição completa, a última em vida do autor, a qual contem 266 receitas), 1732, 1741, 1758,1765, 1794, 1804, 1814, 1832 (duas edições), 1844, 1849, 1987, 1995, 2001, 2008 (Brasil) e 2017 (BRAGA 2017b).

As ervilhas constituíram um dos ingredientes de "carneiro com couve murciana ou com qualquer hortaliça", "caldo de ervilhas" e "de versas quaisquer que quiserem". Foram ainda referidas em um prato de "salsichão com ervilhas" e um de "cardo com ervilhas", ambas na sexta iguaria de um banquete à francesa; as favas foram referenciadas em "favas com ovos" a propósito da primeira coberta do mês de abril e em "quatro pratos grandes de favas com ovos", no banquete para a Quaresma, mas não foram apresentadas as receitas; enquanto o grão-debico consta de seis receitas: "perdiz cozida", "olha moura", "olha francesa", "fina olha moura", "olha podrida em massa" e "olha castelhana" (BRAGA, 2017b). 
Estamos perante um escasso número de receitas, o que se percebe cabalmente, uma vez que o público deste receituário era constituído por cozinheiros de gente abastada, particularmente apreciadora de carne, e por populações monásticas e conventuais interessadas na doçaria mas também nos pratos salgados, como se prova pela cópia sucessiva de receitas incluídas nos seus próprios livros de cozinha manuscritos (BRAGA 2015). Estamos ainda longe da redescoberta do vegetarianismo pelos cozinheiros europeus, de que será exemplo significativo Vincenzo Corrado, através da sua obra Del Cibo Pitagorico Ovvero Erbaceo. Per uso de'Nobili e de'Letterati, publicado em Nápoles, em 1781.

Nos receituários manuscritos, a situação não se alterou. Vejamos alguns exemplos. O que foi compilado pelo franciscano frei Manuel de Santa Teresa, de quem nada sabemos, foi escrito por várias mãos, durante o século XVIII, e apresentou acrescentos. As receitas foram aparecendo por ordem alfabética, embora a partir do fólio 146v, o compilador tenha regressado à letra A. destinava-se ao uso dos franciscanos da província dos Algarves. A obra contém 1014 receitas, das quais apenas 18 (cerca de 1,7 por cento), apresentaram leguminosas: oito com favas (verdes e secas), quatro com feijões (branco e preto), três com grão-de-bico e outras três com lentilhas. Vejamos dois exemplos (BRAGA 2015).

Quadro I

Receitas de Leguminosas num Livro de Cozinha Conventual

\begin{tabular}{|c|c|}
\hline Feijõens pretos & Favas em dia de carne \\
\hline $\begin{array}{l}\text { Depois de cozidos se tirão do fogo e do } \\
\text { mesmo caldo se lhe fas hum molho com } \\
\text { sebola, salsa, pimenta, cravo, gengibre e } \\
\text { cominhos quem lhos quizer deitar alhos } \\
\text { pizados, vinagre de modo que fiquem } \\
\text { picantes a ele sal depois do molho temperado } \\
\text { deitar lhe os feijoens dentro e depois de } \\
\text { ferverem tornem ce a temperar do necesario } \\
\text { e vão } \\
\text { E se quezerem fazer estes mesmos feijoens } \\
\text { que paresão verdes deitem lhe no molho } \\
\text { muita salsa bem picada e fasão lhe o mesmo } \\
\text { tempero mas não levão cominhos. } \\
\text { Todas as tres ou quatro castas de feijoens } \\
\text { cozidos com agoa e sal e postos no prato com } \\
\text { azeite e vinagre e pimenta são bons. }\end{array}$ & $\begin{array}{l}\text { As favas em dia de carne se ham de temperar } \\
\text { com toucinho feito em dados e em o demais } \\
\text { guiza las com sebola, endro, alhos, coentros tudo } \\
\text { verde, caldo de grãos ou agoa bem quente } \\
\text { quanto se cubrão. Tempera las de sal, pimenta, } \\
\text { cravo, gingibre e se lhe quizerem deitar alfaces } \\
\text { coze las primeiro em meyas picadas deitar lhas } \\
\text { dentro e colha las com ovos e azedo e sem as } \\
\text { alfaces são boas e como estiverem cozidas e } \\
\text { temperadas vão a meza. }\end{array}$ \\
\hline
\end{tabular}


Se os livros de receitas apresentam o que se podia cozinhar e consumir e não necessariamente o que se comia, outras fontes revelam a presença e o uso de determinados géneros. Por exemplo, um regimento do Colégio das Artes, em Coimbra, posterior a 1574, patenteou que o peixe fosse acompanhado com uma escudela de abóbora, favas verdes com alface, grão, castanhas piladas ou lentilhas, de acordo com a época do ano (BRANDÃO, 1933, pp. CXXIV-CXXVII). Ou seja, três leguminosas entravam na dieta alimentar dos alunos, na condição de acompanhamentos de pratos de peixe.

Quer os superiores das Ordens quer os bispos ${ }^{8}$ procuravam visitar as casas religiosas, prática a que foi prestada mais atenção após o Concílio de Trento. Em algumas, o que viam era alarmante: disputas nas eleições para abadessa, lutas pelas celas das religiosas que faleciam, cobrança de propinas às noviças quando professavam, violação da clausura, brigas provocadas por ciúmes, insultos e até agressões físicas, posse de animais dentro do convento, realização de comédias e autos em ocasiões festivas, descuidos com os hábitos, uso de cosméticos e até práticas homossexuais, eram bastante mais comuns do que poderíamos pensar. Advertências, censuras e excomunhões, ou seja, mecanismos de coerção, nem sempre eram eficazes, tanto mais que a manutenção dos comportamentos desviantes era uma realidade, bem patente nas visitas e devassas levadas a efeito ao longo da Época Moderna (BRAGA, 2010, pp. 305-322; BRAGA, 2016, pp. 139-169).

Se a prática de visitar as casas religiosas foi anterior ao Concílio de Trento, durante o mesmo insistiu-se nas exigências que deveriam ser tidas em conta no momento de admitir as candidatas a freiras, desde a formação intelectual e doutrinária, o dote, a vocação, passando pela reflexão acerca do ato de professar ${ }^{9}$. Por outro lado, ao relembrar aos bispos e superiores das Ordens a necessidade de visitar as casas e ao tornar essa prática rotineira tentou disciplinar-se o comportamento da população religiosa. Efetivamente, após Trento, o clero desempenhou uma ação mais atuante e efetiva no que se refere ao controlo do comportamento dos fiéis, assunto naturalmente ligado ao discurso de natureza política (CARDIM, 1993, pp. 95-108).

Vejamos um exemplo concreto. Nas visitações da segunda metade do século XVIII, verificou-se que no mosteiro de São Bento de Cástris (Évora), as monjas sofriam privações alimentares, o que também acontecia em outros espaços europeus (CINI, 2009, pp. 235-266; PALOMBO, 2009, pp. 140-160). Em 1797, o visitador, frei Ricardo de Santa Ana, decidiu alertar para a necessidade de cumprir determinados preceitos alimentares, entre os quais referiu duas leguminosas, feijão e grão-de-bico:

\footnotetext{
${ }^{8}$ Sobre a obrigação de visitar os conventos, cf. O Sacrosanto e Ecumenico Concilio de Trento, tomo 2, sessão 25, cap. 11, pp. 381383. Os conventos de jurisdição papal eram governados e visitados pelos bispos. Cf. ZARRI, 1999, pp. 356-364, passim. ${ }^{9}$ Vejam-se as determinações em $O$ Sacrosanto e Ecumenico Concilio de Trento ... cit., tomo 2, sessão 25, cap. 18, pp. 395-397, cap. 20, pp. 399-401.
} 
mandamos que os ditos legumes daqui em diante e o azeite para eles se deem às religiosas e aos padres em cru, querendo-o assim, e na forma seguinte, a cada uma meio alqueire [entre 7 e 9 quilos] de grãos, meio alqueire de feijão branco, meio de castanha seca e alqueire e meio de azeite, porem sempre se farão os de caldeirão para os criados e criadas e para as religiosas que assim os quiserem, mas a estas nunca se darão em cru, para se evitar a desordem e as vontades absolutas de os quererem um dia de uma sorte e outro dia de outra por que isto fará confusão, perturbara a boa ordem e destruirá a economia que sempre deve haver e nós queremos por não ser o nosso ânimo outro mais do que o bem útil das religiosas que assim o requereram, depois de uma séria e madura ponderação como também a respeito da arroba [c.15 quilos] de figos que até agora se lhe dava, pelo que mandamos que de hoje em diante se dê a cada religiosa meia arroba de figos a que chamam de comadre, e meia de passa de uvas das melhores ${ }^{10}$.

Em outros espaços de reclusão, designadamente nos cárceres do Santo Ofício, a presença de leguminosas também se fez sentir na composição das refeições dos presos. Se tivermos em conta as visitas dos inquisidores ao tribunal de Évora, realizadas entre 1720 e 1790, podemos encontrar documentados alguns casos de problemas nos cárceres, os quais ameaçavam a segurança ou pelo menos a saúde dos detidos. Por exemplo, em abril de 1738, o padre João Caetano queixou-se de correntes de ar, pois as janelas não eram calafetadas "que se lhe mandassem por umas portas na janela do cárcere por que lhe fazia mal o ar da noite e que se lhe mandasse dar umas favas que tinha pedido"11. Antes, o depoimento de Charles Dellon, acerca da distribuição dos alimentos aos forçados das galés, entre eles alguns que foram condenados pelo Santo Ofício, permite uma comparação que, se não torna a Inquisição exemplar, também a não coloca em pior situação do que outros espaços prisionais: "cada forçado recebe diariamente uma libra e meia de biscoito [cada libra equivale a 12 ou 16 onças cada ( 0,680 ou 0,489 quilos), ou seja, cada libra significava 5,86 a 8,16 ou 7,82 a 10,88 quilos] muito duro e muito escuro; seis libras de carne salgada por mês e um alqueire de ervilhas, lentilhas ou favas [equivalente a 14 ou 18 litros] de que podem dispor. Os que recebem qualquer ajuda de algures, geralmente vendem estes géneros para comprar qualquer coisa melhor na proporção dos seus meios. Não lhes é fornecido vinho e aqueles que o desejem beber têm de o pagar do seu bolso" (DELLON, 1989, p. 39).

Nos edifícios dos tribunais do Santo Ofício havia, porém, no mínimo duas cozinhas. Uma onde se preparavam as refeições dos presos e outra onde se confecionavam as dos

\footnotetext{
${ }^{10}$ Évora, B.P.E., Cod. CXXXI/2-22, fols 60-60v.

${ }^{11}$ Lisboa, A.N.T.T., Inquisição de Évora, liv. 637, fol. não numerado.
} 
inquisidores. Na Inquisição de Lisboa, na primeira metade do século XVII, sob a tutela de D. Francisco de Castro, havia quatro, funcionando três. A que se destinava ao inquisidor contava com o cozinheiro António Ribeiro e o moço de cozinha Pedro e com utensílios diversificados, a saber, e de entre outros, cepo de picar carne, colheres (uma para manjar branco), cutelos, escumadeiras, facas, formas para pastelões, graais de pedra, grelhas, panelas, pás de ferro, paus de massa e respetivas tábuas, isto é, rolos da massa; pingadeiras, sertãs, tachos, tigelas de cobre, torteiras com e sem tapadouras, sem esquecer braseiros de ferro, fornos de cobre e grelhas (OLIVEIRA, 2000, pp. 10-11). Na despensa podiam encontrar-se especialmente cereais, frutos, leguminosas e peixe seco, a saber: açúcar mascavado, bacalhau, biscoito, cevada, ervilhas, feijões, figos, grãos, lentilhas e passas. Entre os bens não destinados à alimentação contam-se palha e velas (OLIVEIRA, 2000, pp. 11-20).

Fontes de outra natureza revelam igualmente a importância e a presença de determinados géneros alimentares no quotidiano das populações da Época Moderna. Neste caso, referimo-nos aos provérbios. Enquanto elementos da cultura popular, estes são relativamente atemporais no sentido em que aparecem como o resultado da antiga sabedoria, impondo-se, por isso, como argumento de autoridade, veiculando aceções tidas como verdadeiras para diferentes tempos e espaços, não obstante remeterem mais para o passado do que para o comportamento futuro (MATOSO, 1987; COSTA, 1987; LOPES, 1992; VIANA, 1993; BRAGA, 2002, BRAGA, MOURÃO, 2015). Podem assumir a função de apresentar admoestações, conselhos, críticas, doutrinas, informações e regras práticas e caracterizam-se, de entre outros aspetos, por se apresentarem no tempo presente, expressando verdades sempre válidas (SCHMIDT-RADEFELDT, 1984, p. 216). Descrevem estados de coisas gerais, não admitindo leituras episódicas só compreensíveis num espaço ou num tempo. No entanto, se uns suscitam uma interpretação literal, outros desencadeiam a necessidade de uma interpretação figurada (LOPES, 1992, p. 21). São textos curtos, com uma estrutura concisa, anónimos, ou melhor, da autoria da respetiva comunidade linguística e cultural, os quais fazem circular uma experiência coletiva (SCHMIDT-RADEFELDT, 1984, p. 213), o que não impede a semelhança de provérbios da autoria de comunidades diferentes (GHITESCU, 1991; FUNK, 2000, СНАСОТО, 2011).

Partindo do corpus paremiológico português da Época Moderna, designadamente das compilações de provérbios de António Delicado (DELICADO, 1651, pp. 78, 81, 123, 200) e de Rafael Bluteau (BLUTEAU, 1713, p. 44), que apresentou, em várias entradas, diversos provérbios relativos à temática em estudo, vejamos o entendimento que, então, se tinha das leguminosas. Advirta-se desde já que o discurso proverbial assume os sentidos literal e figurado, uma vez que os alimentos, além de apresentarem qualidades nutricionais muito variadas, evidenciam valores simbólicos igualmente distintos, de tal modo que se verificou sempre uma hierarquia de consumos relacionada diretamente com a raridade e com o preço dos géneros, tornando claro que determinados gastos eram socialmente prestigiantes. 
O levantamento dos provérbios nos dois textos deu magros resultados, um total de oito provérbios, quatro em cada autor, mas correspondentes a seis unidades diferentes. Se compararmos com os que se relacionam com carne, peixe ou fruta, pode observar-se que a presença das leguminosas - e apenas foram referidas as favas - é muito limitada em termos relativos e em termos absolutos (BRAGA, 2017c). Não esqueçamos que uma das fontes de Rafael Bluteau foi a obra do próprio António Delicado. No entanto, o autor integrou outros provérbios que, entretanto, conseguiu arrolar. E não esqueçamos também que as leguminosas, sendo de consumo corrente não eram dos alimentos mais apreciados.

Quadro II

Provérbios sobre Leguminosas em António Delicado e em Rafael Bluteau

\begin{tabular}{|l|l|}
\hline \multicolumn{1}{|c|}{ António Delicado } & \multicolumn{1}{c|}{ Rafael Bluteau } \\
\hline - Como vires ao faval, assim espera o al & - Como vires ao faval, assim espera o al \\
- Menina e vinha, peral e faval, maus são de & - Ir à fava é mandar brincar \\
guardar & - Em cada casa comem favas, e na nossa às \\
- Em cada casa comem favas, e na nossa às & caldeiradas \\
caldeiradas & - Favas das mais caras, cerejas das mais baratas \\
- Favas das mais caras, cerejas das mais baratas & \\
\hline
\end{tabular}

O provérbio é um texto breve, anónimo, institucionalizado e que compagina assunções comummente aceites como verdadeiras, pelo que subsiste como um elemento didático e doutrinal, na medida em que funciona como "mensageiro" do substrato axiológico do coletivo. A tipologia proverbial tem carácter dicotómico, ou seja: provérbios do tipo descritivo e provérbios do tipo normativo. No primeiro caso, pense-se, por exemplo em "Menina e vinha, peral e faval, maus são de guardar", e, no segundo, em provérbios como "Favas das mais caras, cerejas das mais baratas". A maioria denota aspetos ou normas da esfera quotidiana, sobretudo no domínio das relações interpessoais, das hierarquias no seio familiar e da casa, do que é ou não convencional em matéria de comportamento, da aparência, etc. Se entendermos o processo analítico, com recurso à distribuição das ocorrências proverbiais por três itens, favorável, desfavorável e não aplicável, teremos alusões às expetativas - "Como vires ao faval, assim espera o al" - ao preço elevado ou baixo conforme as espécies e à consideração, dando mesmo conselhos - "Favas das mais caras, cerejas das mais baratas" - à empáfia - "Em cada casa comem favas, e na nossa às caldeiradas" - e à desconfiança que, também configura a possibilidade de alguém cobiçar - "Menina e vinha, peral e faval, maus são de guardar". No item não aplicável poderemos incluir as ocorrências que suscitam dúvidas interpretativas, as que não apresentam indicadores inequivocamente positivos ou negativos, caso de "Ir à fava é mandar brincar", que assumirá, futuramente, uma conotação bastante negativa. 
4. No Brasil, no passado como no presente, uma leguminosa impôs-se: o feijão. De consumo corrente e quotidiano e com diversas variedades, cores e sabores, pode ser degustado em preparações diversas com destaque para a feijoada e para o feijão com arroz. $\mathrm{O}$ consumo desta leguminosa foi notado por nacionais e por viajantes estrangeiros que visitaram o Brasil desde o século XVI. Se José de Anchieta, em 1554, depois de referir o consumo corrente da mandioca, salientou que a parte mais importante do sustento quotidiano "consiste em legumes e favas, em abóboras e outras que a terra produz, em folhas de mostarda e outras ervas cozidas" (ANCHIETA, 1988, pp. 53-54), já em relação ao Brasil holandês, segundo Joan Nieuhof os negros comiam batatas, feijão, farinha, mandioca, canade- açúcar e peixe (NIEUHOF, 1981, p. 39). No recôncavo baiano, igualmente os negros, na centúria seguinte, segundo Antonil, alimentavam-se de mandioca, raízes, caranguejos e outros mariscos dos mangues, feijão, aipim e batata. Bebiam garapa, ou seja caldo de cana na forma de espuma, que podia ser doce ou azedo, e aguardente (ANTONIL, 1992, pp. 92, 121).

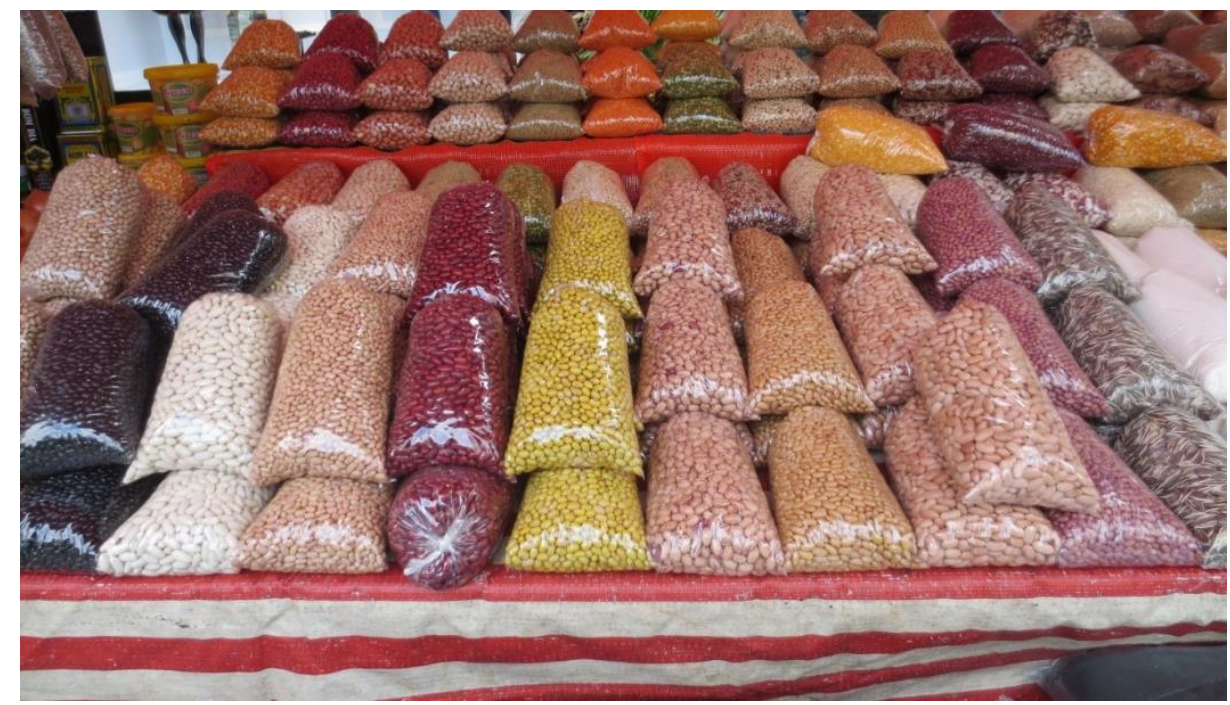

Fig. 1 - Feijões na feira dominical da Alameda Lorena (São Paulo), em maio de 2017. Foto de IDB.

Para Rugendas, já no século XIX, ficou claro que os escravos vindos de África e vendidos nos mercados do Rio de Janeiro eram alimentados com farinha de mandioca, feijão e carne seca a par de frutas refrescantes. Nas fazendas, almoçavam às 8 horas e jantavam ao meio dia (RUGENDAS, s.d., p. 234). Enquanto pessoas pobres, estavam dependentes dos géneros que os seus senhores lhes destinavam. A recoleção de frutos e legumes e, eventualmente, alguma caça e pesca poderiam compor a alimentação de alguns. $\mathrm{O}$ mesmo Rugendas não deixou de 
notar que os senhores lhes forneciam farinha de mandioca, feijão, carne seca, toucinho e bananas e que "em geral, a alimentação que lhes dão é muito parcimoniosa e seria apenas suficiente se não tivessem a possibilidade de melhorá-la com frutas, legumes selvagens e mesmo caça" (RUGENDAS, s.d., 238). Pohl, por seu turno, durante a presença da Corte, deu conta que, no Rio de Janeiro, o prato predileto do português pobre e o único sustento do trabalhador e do escravo era o feijão (POHL, 1951, p. 95).

Segundo Mawe, em texto de 1812, em Minas Gerais, os negros não beneficiavam de grande diversidade alimentar, pois almoçavam farinha de milho misturada com água quente e pedaços de toucinho e jantavam feijão (MAWE, 1944, p. 129). Saint-Hilaire, igualmente no século XIX, referindo-se ao distrito diamantino, concretizou que cada negro recebia um quarto de alqueire de fubá, uma certa quantidade de feijão e um pouco de sal. Quando havia falta de feijão, o mesmo era substituído por carne. Os negros comiam três refeições, cozinhavam à noite e, por vezes, os combustíveis eram ervas (SAINT-HILAIRE, 2004, p. 16). Em algumas localidades mineiras havia plantações específicas para os negros. Os escravos alimentavam-se das produções locais como farinha de mandioca, milho, angu de fubá cozido em água, feijão preto esporadicamente cozinhado com toucinho e outras carnes, sal e aguardente. A completar a alimentação, a caça de aves como perdizes e codornizes, a par de animais de pelo como veados e ainda frutas diversas: abacaxis, bananas, cajus, jabuticabas, limões, mangabas e melancias. Quando os escravos adoeciam, eram-lhes fornecidos outros produtos, visando manter as forças dos enfermos: açúcar, agrião, aguardente, arroz, aveia, carne, carne seca, chá, galinhas, sal, toucinho, rapadura e vinho, sem esquecer tabaco, entendido como um bem com qualidades energizantes (SCARANO, 1994, pp. 40-65). Provenientes de diferentes povos de África, os negros eram oriundos especialmente das regiões Congo e da Costa da Mina e começaram a chegar logo no século XVI para trabalhar nos engenhos de açúcar. Tiveram que aceitar diferentes hábitos alimentares, não só pela condição de escravos como também pela inexistência de alguns produtos das suas terras de origem. Efetivamente, importa lembrar que, numa primeira fase, exportava-se mandioca do Brasil para África e que, posteriormente, mandioca, milho, batata-doce e alguns frutos americanos passaram a ser plantados em África (ALENCASTRO, 2000, p. 254).

Quando a Corte se fixou no Rio de Janeiro, os brancos, especialmente os mais abastados, mostraram alguma repugnância em adotar certas comidas brasileiras, bem como algumas técnicas culinárias. Foi sintomática a observação de Luís Joaquim dos Santos Marrocos, em 1813:

aqui, comparada a natureza de um e outro país, não é mais favorável o preço dos géneros de primeira necessidade; e muito pior para os europeus, que, na frase dos cariocas, são esdrúxulos, isto é, que não podem acostumar o seu paladar e estômago à diversidade económica de 
comeres que nauseia e enfastia, como é por exemplo o trivial quitute de carne seca de Minas com feijão negro e farinha de pau, tudo cozido e amassado com os dedos, que por fim são lambidos. Entre esta gente chama-se quitute ao que entre nós se dá o nome de acepipe ou pitéu (Cartas de Luiz, p. 153).

Mas o feijão imperava. Pohl, referindo-se igualmente ao Rio de Janeiro, salientou a simplicidade da mesa mesmo em casas de distinção. Referiu o consumo de frango assado ou cozido com arroz e acrescentou que o prato preferido dos brasileiros era "o pouco digerível arroz. A água em que ele é cozido, não é coada. Nela se derrete uma grande concha de ferro de toucinho e mistura-se quente com o feijão e depois come-se com farinha de milho ou de mandioca, servindo-se dela cada um à sua vontade. Acrescenta-se às vezes paçoca. As frutas em conserva também pertencem aos alimentos favoritos" (POHL, 1951, p. 88). Spix e Martius, no início do século XIX, forneceram mais detalhes acerca da alimentação no Rio de Janeiro: "a mandioca, o fubá e o feijão preto, em geral cozidos com toucinho e carne seca ao sol e salgada, formam a principal parte do embora pesado e grosseiro alimento, mas saudável para quem faz muito exercício e toma vinho português ou cachaça" (SPIX, MARTIUS, vol. 1, 1981, p. 160). Referindo-se aos remediados, Debret, na década de 1830, descreveu os jantares dos negociantes como refeições compostas por:

um miserável pedaço de carne seca, de três a quatro polegadas quadradas e somente meio dedo de espessura; cozinham-no a grande água com um punhado de feijões pretos, cuja farinha cinzenta, muito substancial, tem a vantagem de não fermentar no estômago. Cheio o prato com esse caldo, no qual nadam alguns feijões, joga-se nele uma grande pitada de farinha de mandioca, a qual, misturada com os feijões esmagados forma uma pasta consistente que se come com a ponta da faca arredondada, de lâmina larga [...]. Mais abastado, o negociante acrescenta à refeição o lombo de porco assado ou o peixe cozido na água com um raminho de salsa, um quarto de cebola e três ou quatro tomates. Completam a refeição bananas e laranjas. Bebe-se unicamente água (DEBRET, 1940, p. 139).

Mudando de localização e dirigindo-nos a sul, o relato de Mawe deu conta de algumas refeições festivas praticadas em São Paulo: 
o pão é muito bom e a manteiga tolerável, mas usada raras vezes; exceto no café da manhã e no chá à noite. Prato bastante comum, no almoço, é uma variedade de ervilhas, muito gostosa, denominadas feijão, cozida ou misturada com farinha de mandioca. $O$ jantar servido usualmente ao meio-dia, ou mais cedo, consiste em geral, numa quantidade de verduras fervidas com carne de porco gorda, ou bife, uma raiz da espécie da batata e uma galinha recheada, com excelente salada, seguida por grande variedade de deliciosas conservas e doces. Tomam muito pouco vinho às refeições. A bebida usual é a água. Em ocasiões públicas ou quando se oferece uma festa a muitos convidados, ornamenta-se a mesa sumptuosamente; servem-se de uma só vez, de trinta a cinquenta pratos; arranjo pelo qual se evita uma série de mudanças de pratos. $O$ vinho circula copiosamente, repetindo-se os brindes durante o banquete, que dura, em geral, de duas a três horas, seguido de doces, o orgulho da mesa; depois do café, os convidados passam a noite dançando, ouvindo música ou jogando cartas (MAWE, 1944, p. 92).

Outras fontes, já tratadas, demonstram que em São Paulo, os almoços servidos entre as 8 e as 9 horas da manhã eram compostos por milho (farinha ou canjica), feijão (caldo com torresmo, ou tutu, também denominado virado), couve picada, arroz e carne de porco (enchidos e carne conservada em banha). Ovos estrelados podiam acompanhar almoços e jantares. Laranjas acompanhavam o virado, bananas escoltavam o feijão ou, em alternativa, podiam ser cozidas ou fritas e polvilhadas com açúcar e canela. Neste caso constituíam uma sobremesa. Os jantares, servidos entre as 13 e as 14 horas, poderiam compreender feijão, arroz, carne assada no forno, cuscuz, canjica dura, e doces de ovos. Aboborinhas, agriões, almeirões, batatas-doces, carás, mingau de milho verde e palmito plausivelmente estariam também presentes. Em dias festivos, cuscuz de carne, peixe fresco, arroz com frango, frango assado e recheado e leitoa pautavam em mesas não populares. Entre as sobremesas canjica com leite e açúcar ou com melado, melado com farinha ou melado de cará. À noite, nas merendas apresentavam-se iguarias como amendoim torrado, batata-doce, paçoca de amendoim, pinhão e pipoca (ALMEIDA, 1998, 25-29).

Encaminhando-se em outra direção, o naturalista Auguste de Saint-Hilaire, em 1819, descreveu os hábitos alimentares dos habitantes do Rio Grande do Norte: "até mesmo as pessoas relativamente abastadas só usam na sua mesa feijão, carne de porco, arroz, leite, queijo e canjica", apesar de possuírem gado. A produção de queijo seria relevante. Era feito com coalho de capivara e com recurso a formas de madeira de forma circular, semelhantes às que eram utilizadas para o queijo de Minas. A "consistência é compacta, sua cor se aproxima 
da dos queijos Gruyères, mas o tom amarelo é mais pronunciado ao que me parece. Seu sabor é suave e agradável" (SAINT-HILAIRE, 2004, p. 52).

E os exemplos poderiam continuar. No entanto, o que importa ressaltar é o seguinte: independentemente das variações significativas que se verificavam entre as diversas regiões do Brasil e as abruptas clivagens sociais entre escravos, remediados e abastados, uma leguminosa parece estar sempre ou quase sempre presente nas refeições, em especial nas que eram de consumo corrente, de norte a sul do Brasil: o feijão.

5. Sem qualquer intuito de explorar exaustivamente as fontes apresentadas e analisadas pretendeu-se dar a conhecer algumas das possibilidades que as mesmas oferecem para o estudo da presença das leguminosas nas mesas portuguesas da Época Moderna. A literatura, os livros de receitas, os relatos dos estrangeiros ou ainda os livros de visitas a instituições diversas, os de compras, e tantas outras constituem repositórios muito relevantes que importa explorar. Dessa riqueza se identificaram vários exemplos que se procuraram contextualizar e explicar.

A presença e também a ausência das leguminosas nas referidas fontes constituem um indício claro do valor simbólico destes alimentos. Efetivamente, quer em Portugal quer no Brasil, as leguminosas, embora presentes nas mesas de pobres e de abastados, estiveram afastadas das refeições festivas e dos momentos de requinte. O seu consumo, no passado como no presente, está muito mais ligado à prática e ao imaginário dos grupos populares.

As aparentemente desprezadas refeições à base de leguminosas, não deixam contudo, de ser particularmente ricas do ponto de vista nutricional e também - não obstante as compreensíveis diferenças de gostos - apreciadas na alimentação quotidiana dos diferentes setores sociais, como nos demonstram as ementas dos restaurantes da atualidade, quer os mais populares quer os mais sofisticados, muitas vezes com recriações pessoais da autoria dos respetivos chefs. Um exemplo relevante é o dos restaurantes Piselli e Piselli Sud, em São Paulo, nos quais os pratos são decorados com uma ervilha - leguminosa que dá o nome ao restaurante - em homenagem ao trabalho inicial de Jucelino Pereira, isto é, o cultivo daquele alimento no interior de São Paulo ${ }^{12}$.

\footnotetext{
${ }^{12} \mathrm{Cf} .<$ http://www.piselli.com.br/piselli-sud/>. Consultado a 20 de agosto de 2017.
} 


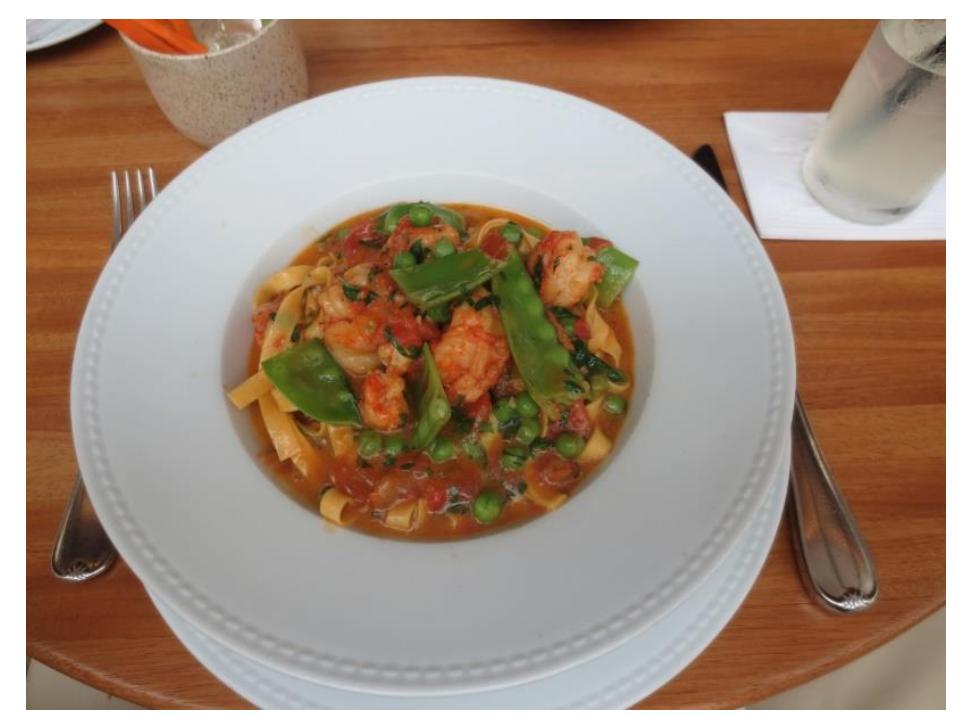

Fig. 2 - Pasta e piselli con scampi, do restaurante Piselli Sud, de São Paulo, em maio de 2017. Foto de IDB.

Bem conhecidos por todos os Portugueses salientem-se diversos pratos e sobremesas preparados com leguminosas, tais como "sopa de ervilhas", "sopa de favas", "sopa de grão com espinafres", "sopa de feijão encarnado com carnes", "ervilhas guisadas com ovos escalfados", "favas guisadas com enchidos", "meia desfeita de bacalhau com grão", "feijoada" e, para sobremesa, pastéis de feijão ou, pelo Natal, azevias de grão. Menos adeptos terão as lentilhas. Em sentido contrário, não se podem esquecer os muito populares tremoços, sempre presentes nas cervejarias. Relevante é, cada vez mais, a soja, em particular entre todos os que seguem regimes vegetarianos ou vegans, independentemente de todas as leguminosas poderem ser consumidas pelos partidários da dieta verde. Finalmente, refira-se que, uma parte significativa destes pratos referidos já se preparava durante a Época Moderna, como se pôde verificar pelas duas receitas apresentadas, matéria desafiante que pode também ser objeto de aprofundamento.

\section{Referências}

\section{Fontes Manuscritas}

Évora, Biblioteca Pública de Évora

Cod. CXXXI/2-22, fols 60-60v.

Lisboa, Arquivos Nacionais Torre do Tombo

Inquisição de Évora, liv. 637. 


\section{Fontes Impressas}

ANCHIETA, José de. Cartas, Informações, Fragmentos Históricos e Sermões. Belo Horizonte: Itatiaia, São Paulo: Editora da Universidade de São Paulo, 1988. Original do século XVI.

ANTONIL, André João. Cultura e Opulência do Brasil. 3. ${ }^{\text {a }}$ edição. Belo Horizonte: Itatiaia, São Paulo: Editora da Universidade de São Paulo, 1992. A primeira edição é de 1711.

BLUTEAU, Rafael. Vocabulario Portuguez e Latino. vol. 4. Coimbra: Colégio das Artes, 1713.

BUARCOS, João Brandão de. Grandeza e Abastança de Lisboa em 1552. Lisboa: Livros Horizonte, 1990. Original de 1552.

Cartas de Luiz Joaquim dos Santos Marrocos. Anais da Biblioteca Nacional do Rio de Janeiro, vol. 56, Rio de Janeiro, 1934 [1939].

DEBRET, Jean Baptiste. Viagem Pitoresca e Histórica ao Brasil. Tradução e notas de Sérgio Milliet. São Paulo: Livraria Martins, 1940. A primeira edição é de 1834-1939.

DELICADO, António. Adagios Portugueses reduzidos a Lugares communs, nova edição revista e prefaciada por Luís Chaves. Lisboa: Livraria Universal, 1923. A primeira edição é de 1651.

DELLON, Charles. De Goa a Lisboa 1676-1677. Portugal nos séculos XVII e XVIII. Apresentação tradução e notas de Castelo-Branco Chaves. Lisboa: Lisóptima, 1989.

FERREIRA, Armando. O Casamento de Fifi Antunes. Lisboa: Livraria Guimarães, 1935.

LIMPO, Berta Rosa. O Livro de Pantagruel: Cozinha. Doçaria. Bebidas. Lisboa: Editorial Século, 1945.

MAWE, John. Viagem ao Interior do Brasil, principalmente aos Distritos de Ouro e dos Diamantes. Tradução de Solena Benevides Viana. Introdução e notas de Clado Ribeiro de Lessa. Rio de Janeiro: Zélio Valverde, 1944. A primeira edição é de 1812.

Modas e Bordados. Lisboa, n. ${ }^{\circ}$ 1786, de 01de maio de 1946.

NIEUHOF, Joan. Memorável Viagem Marítima e Terrestre ao Brasil. Tradução de Moacir N. Vasconcelos. Belo Horizonte: Itatiaia, São Paulo: Editora da Universidade de São Paulo, 1981. A primeira edição é de 1682. 
POHL, Johan Emanuel. Viagem no Interior do Brasil empreendida nos anos de 1817 a 1821. vol. 1. Rio de Janeiro: Instituto Nacional do Livro, 1951. A primeira edição é de 1832-1837.

RUGENDAS, Johann Moritz. Viagem Pitoresca através do Brasil. Tradução de Sérgio Milliet. São Paulo: Círculo do Livro [s.d.]. A primeira edição é de 1835.

Sacrosanto (O) e Ecumenico Concilio de Trento em Latim e Portuguez. tomo 2. Lisboa: Oficina Patriarcal de Francisco Luís Ameno, 1781.

SAINT-HILlAIRE, Auguste de. Viagem às nascentes do Rio São Francisco. Tradução de Regina Regis Junqueira. 2. a edição, Belo Horizonte: Itatiaia, 2004. A primeira edição é de 1847.

SAINT-HILlAIRE, Auguste de. Viagem pelo Distrito dos Diamantes e Litoral do Brasil. Tradução de Leonam de Azevedo Penna. Belo Horizonte: Itatiaia, 2004. A primeira edição é de 1833.

SOUSA, Amílcar de. “O Feijão”. O Vegetariano. Vol. 8, n. ㄱ, Porto, 1917, p. 269.

SPIX, Johann Baptist von, MARTIUS, Carl Friedrich von. Viagem pelo Brasil 1817-1820. Tradução de Lúcia Furquim Lahmeyer. Revisão de B. F. Ramiz Galvão. Anotações de Basílio Magalhães. 3 vols. Belo Horizonte: Itatiaia, São Paulo: Universidade de São Paulo, 1981. A primeira edição é de 1823.

\section{Estudos}

ALENCASTRO, Luiz Felipe de. O Trato dos Viventes: Formação do Brasil no Atlântico Sul (séculos XVI-XVII). 2. ${ }^{\mathrm{a}}$ edição. São Paulo: Companhia das Letras, 2000.

ALMEIDA, Aloísio. Vida Cotidiana da Capitania de São Paulo (1722-1822): Excertos de uma Obra Completa. Vida Cotidiana em São Paulo no século XIX: Memórias, Depoimentos, Evocações. Organização de Carlos Eugénio Marcondes de Moura. São Paulo: Ateliê Editorial, Fundação Editora da UNESP, Imprensa Oficial do Estado, Secretaria de Estado da Cultura, 1998, pp. 3-75.

BRAGA, Isabel Drumond. Conventos femininos e religiosidade subvertida: Évora séculos XVII e XVIII. Jacqueline Hermann e William de Souza Martins (dir.). Poderes do Sagrado. Europa Católica, América Ibérica, África e Oriente portugueses (séculos XVI-XVIII). Rio de Janeiro: Multifoco, 2016, pp. 139-169.

BRAGA, Isabel Drumond. A Mesa Lisboeta na ficção de Armando Ferreira (1893-1968). Conferência apresentada ao II Simpósio Internacional de Património e Cultural Alimentar: os desafios e as delícias dos múltiplos sabores culinários - Curitiba, 6 a 9 de junho de 2017a. 
BRAGA, Isabel Drumond. Castela e os Castelhanos nos Provérbios Portugueses. In Cooperação e Conflito. Portugal, Castela e Aragão (séculos XV-XVII). Lisboa: Universitária Editora, 2002, pp. 261-271.

BRAGA, Isabel Drumond. Domingos Rodrigues e a Arte de Cozinha: uma vida pouco conhecida, uma obra muito usada. In Arte de Cozinha, Lisboa: Círculo de Leitores, 2017b, pp.7-48.

BRAGA, Isabel Drumond. Alimentação e paremiologia no Portugal Moderno: 'o hóspede e o peixe aos três dias fede'. II Seminário Internacional de História da Alimentação e Cultura Material: circulação de artefactos, saberes e fazeres - Campinas, Unicamp, 3 a 5 de maio 2017c.

BRAGA, Isabel Drumond. Sabores e Segredos: Receituários Conventuais Portugueses da Época Moderna. Coimbra: Imprensa da Universidade de Coimbra, Annablume, 2015.

BRAGA, Isabel Drumond. Vaidades nos Conventos Femininos ou das Dificuldades em deixar a Vida Mundana (séculos XVII-XVIII). Revista de História da Sociedade e da Cultura, vol.10, tomo 1, Coimbra, 2010, pp. 305-322. Disponível em https://www.academia.edu/6555044/.

BRAGA, Isabel Drumond, CASTRO, Inês de Ornelas. Saberes e Fazeres de Berta Rosa Limpo. A Construção de um Êxito: o Livro de Pantagruel. Faces de Eva, n. ${ }^{\circ}$ 29, Lisboa, 2013, pp. 45-66.

BRAGA, Isabel Drumond, MOURÃO, Maria Elsa. Género e Discurso Proverbial no Portugal Moderno. Faces de Eva n. ${ }^{\circ}$ 33, Lisboa, 2015, pp. 83-102.

BRANDÃO, Mário. O Colégio das Artes (1555-1580). Coimbra: Imprensa da Universidade, 1933.

CARDIM, Pedro. Politics and Power Relations in Portugal (Sixteenth-Eighteenth Centuries). Parliaments. Estates and Representations, vol. 13, n. ${ }^{\circ}$ 2, Londres, 1993, pp. 95-108.

CHACOTO, Lucília. Semelhanças e diferenças dos provérbios meteorológicos no espaço lusófono". GARGALHO GIL, José Enrique et alii (dir.). I Proverbi Meteoroligici: ai confini dell'Europa Romanza. Alessandria: Edizioni dell'Orso, 2011, pp. 1-14.

CHARTIER, Roger. Debate: História e Literatura. Topoi, n. ${ }^{\circ}$ 1, Rio de Janeiro, 2000, pp. 197-216.

CINI, Marco. Economia, Muliebre e Religiosa. Note sulle Vicendi Patrimoniali del Monastero di Sant'Anna di Pisa nel XVIII secolo. In AGLIETI, Marcella (dir.). Nobildonne, Monache e Cavaliere dell'Ordine di Santo Stefano: Modelli e Strategia Femminili nella Vita Publica della Toscana Granducale. Pisa: Edizione ETS, 2009, pp. 235-266

COSTA, H. La Réprésentation du Corps dans la Littérature Populaire Portugaise: Le Discours Proverbial. In Littérature Orale Tradicionalle Populaire. Actes du Colloque. Paris: Fundação Calouste Gulbenkain, 1987, pp. 561-576. 
ESPERANÇO, Ricardo Manuel Pereira. Lisboa em Camisa: palco e personagens na obra de Gervásio Lobato, Lisboa, Livros Horizonte, 2017.

FONSECA, Luís Adão da. As Relações entre História e Literatura no contexto da actual crise da dimensão social da narrativa historiográfica. In Actas do Colóquio Internacional Literatura e História. vol. 1, Porto, 2004, pp. 265-278.

FUNK, Gabriela. O Provérbio como Ponte entre diferentes Culturas. In SIEPMANN, Helmut (org.). Portugal, Indien und Deutschland. Portugal, India e Alemanha. Akten der V. DeutschPortugiesischen Arbeitsgespräche. Actas do V Encontro Luso-Alemão. Köln: Zentrum Portugiesischsprachige Welt. Lisboa: Centro de Estudos Históricos da Universidade Nova de Lisboa, 2000, pp. 345-353.

GHITESCU, Micaela. Os Provérbios. Traço de União entre Irmãos. Nós. Revista de Lusofonia. Vol. 19-20, Pontevedra, Braga, 1991, pp. 357-360.

LIMA, Valéria. J.-B. Debret Historiador e Pintor. Campinas: Editora Unicamp, 2007.

LOPES, Ana Cristina Macário. Texto Proverbial Português. Elementos para uma Análise Semântica e Pragmática. Coimbra: Dissertação de Doutoramento em Linguística Portuguesa apresentada à Faculdade de Letras da Universidade de Coimbra 1992.

MARTINS, Luciana de Lima. O Rio de Janeiro dos Viajantes. O Olhar Britânico (1800-1850). Rio de Janeiro: Zahar Editor, 2001.

MATOS, Sérgio Campos de. História, Memória e Fiç̧ão: que fronteiras? História e Historiografia, n. ${ }^{\circ}$ 17, Ouro Preto, 2015, pp. 414-426.

MATTOSO, José. O Essencial sobre os Provérbios Medievais Portugueses. Lisboa: Imprensa Nacional Casa da Moeda, 1987.

OLIVEIRA, Maria do Rosário Álvaro de Oliveira Mendes de. D. Francisco de Castro e o Morgado do 'Menor' D. João de Castro Telles Meneses Henriques (1641-1654). 2 vols. Lisboa: Dissertação de Mestrado em História Moderna apresentada à Faculdade de Letras da Universidade de Lisboa, 2000 .

PALOMBO, Irene. 2009. Il Sistema dei Monasteri Femminili in una Terra di Confine. La Diocesi di Sora, Aquino e Pontecorvo, Veneza, Dottorato di Ricerca in Storia Social Europea dal Medioevo all'Età Contemporanea, Università Ca'Foscari Venezia, 2009.

PESAVENTO, Sandra Jatahy. O Mundo como Teatro: Leituras da História e da Literatura. História da Educação, n. ${ }^{\circ}$ 14, Pelotas, 2003, pp. 31-45. 
ROSSATO, Luciana. A Lupa e o Diário. História Natural, Viagens Científicas e Relatos sobre a Capitania de Santa Catarina (1763-1822). Itajaí: Universidade do Vale de Itajaí, 2007.

SCARANO, Julieta. Cotidiano e Solidariedade. Vida Diária da Gente de Cor nas Minas Gerais. Século XVIII, São Paulo, Editora Brasiliense, 1994.

SCHMIDT-RADEFELDT, Jiirgen. Descrição Semântica e Funções Semanfóricas do Provérbio. In J. Schmidt-Radefeldt e José G. Herculano de Carvalho (orgs.). Estudos de Linguistica Portuguesa. Coimbra: Coimbra Editora, 1984, pp. 201-223.

VELOSO, Carlos. A Alimentação em Portugal no século XVIII nos relatos dos viajantes estrangeiros. Coimbra: Minerva História, 1992.

ZARRI, Gabriella. Ordine Religiosi e Autorità Episcopali : le Visite Pastorali a Chiese Esenti e Monasteri. In NUBOLA, Cecilia, TURCHINI, Angelo (dir.). Fonti Ecclesiastiche per la Storia Sociale e Religiosa d'Europa: XV-XVII secolo, Bolonha: Il Mulino, 1999, pp. 356-364.

\section{Webgrafia}

$<$ http://www.dgs.pt/promocao-da-saude/educacao-para-a-saude/areas-deintervencao/alimentacao.aspx) >. Consultado a 20 de setembro de 2016.

<http://www.piselli.com.br/piselli-sud/>. Consultado a 20 de agosto de 2017.

<http://www.unric.org/pt/actualidade/32128-2016-e-ano-internacional-das-leguminosas $>$. Consultado a 20 de setembro de 2016.

<https://www.movimento2020.org/os-desafios/descubra-os-desafios-2020/aumentar-oconsumo-de-leguminosas $>$. Consultado a 20 de setembro de 2016.

<www.vidaativa.pt/a/importancia-das-leguminosas/. Consultado a 20 de setembro de 2016. http://www.colegiof3.ulisboa.pt/pt/nots/fava.php>. Consultado a 20 de setembro de 2016. 